\title{
Neuromyelitis optica with very late onset
}

\author{
Neuromielite óptica de início tardio \\ Cristiane Serra Souza', Joseph Bruno Bidin Brooks ${ }^{2,3}$, Celso Luis Silva Oliveira ${ }^{1,3}$, Yara Dadalti Fragoso ${ }^{2,3}$ \\ ${ }^{1}$ Department of Neurology, Ana Costa Hospital, Santos SP, Brazil; \\ ${ }^{2}$ Department of Neurology, Universidade Metropolitana de Santos (UNIMES), Santos SP, Brazil; \\ ${ }^{3}$ Multiple Sclerosis Reference Center for the Coastal Region of the State of São Paulo, Santos SP, Brazil. \\ Correspondence: Yara Dadalti Fragoso; Department of Neurology, Medical School, UNIMES; Rua da Constituição 374; 11015-470 Santos SP - Brasil; \\ E-mail:yara@bsnet.com.br \\ Conflict of interest: There is no conflict of interest to declare. \\ Received 29 May 2012; Received in final form 23 March 2013; Accepted 01 April 2013
}

Neuromyelitis optica (NMO or Devic's disease) is a relative rare relapsing inflammatory disorder of the central nervous system that closely resembles multiple sclerosis ${ }^{1}$. Strong evidence indicates that aquaporin 4 antibodies (NMO-IgG) have a pathogenic role in NMO and serve as a useful diagnostic marker. The well-established diagnostic criteria for definitive $\mathrm{NMO}$, which are accepted worldwide, include optic neuritis, myelitis and, at least, two of the following three supportive criteria: magnetic resonance image (MRI) evidence of a contiguous spinal cord lesion that is three or more segments in length, brain MRI that does not fulfill the diagnosis criteria for multiple sclerosis, or NMO-IgG seropositivity².

Several studies have shown that the onset of NMO is predominant in the second and third decades of life, and this result have been confirmed in three classical Brazilian studies on the subject ${ }^{3-5}$. Only five cases of NMO developing after the age of 70 years have been reported ${ }^{6-11}$. The present study describes another case of $\mathrm{NMO}$ with onset at the age of 75 years.

A female patient aged 75 years presenting with blurred vision in the right eye and weakness in both legs was seen at the Emergency department. These symptoms became established over a 24-hour period. She presented diabetes mellitus type II, high blood pressure and visual loss in the left eye, secondary to toxoplasmosis that had started two years earlier. The patient's condition progressed, with urinary retention and worsening of her paraparesis, such that her maximum sensory level became T4. Her brain MRI showed leukoaraiosis, and the spinal fluid analysis showed 58 cells ( $22 \%$ neutrophils, $78 \%$ lymphocytes), glucose $56 \mathrm{mg} \%$, proteins $117 \mathrm{mg} \%$ and was negative for syphilis, bacteria, fungi and oligoclonal bands. Her blood analysis was IgM positive for toxoplasmosis and CMV, and negative for HIV, HTLV I and II, rheumatoid factor and anti-nucleus factor. Carotid ultrasound, blood cell counts and serum biochemical analysis were unremarkable. Electrophysiological studies showed no peripheral neuropathy or myopathy. NMO-IgG was positive, detectable at concentrations of 1:160. Her spinal cord MRI showed an extensive lesion, enhanced by gadolinium (Figure).

The patient was treated with intravenous corticosteroids (pulse therapy for five days) followed by intravenous human immunoglobulin for five days. Her visual deficit showed some improvement and she was released from the hospital with oral corticosteroids prescribed. Four months later, the patient was seen to be continuing to show progressive but slow improvement. Toxoplasmosis was considered to be an additional hazard for immunosuppression and, therefore, treatment has been mainly based on rehabilitation, since immunosuppression is not an option for this patient.

The present case shows that NMO must be considered as a differential diagnosis in any patient presenting optical neuritis and/or myelitis, irrespective of the patient's age.
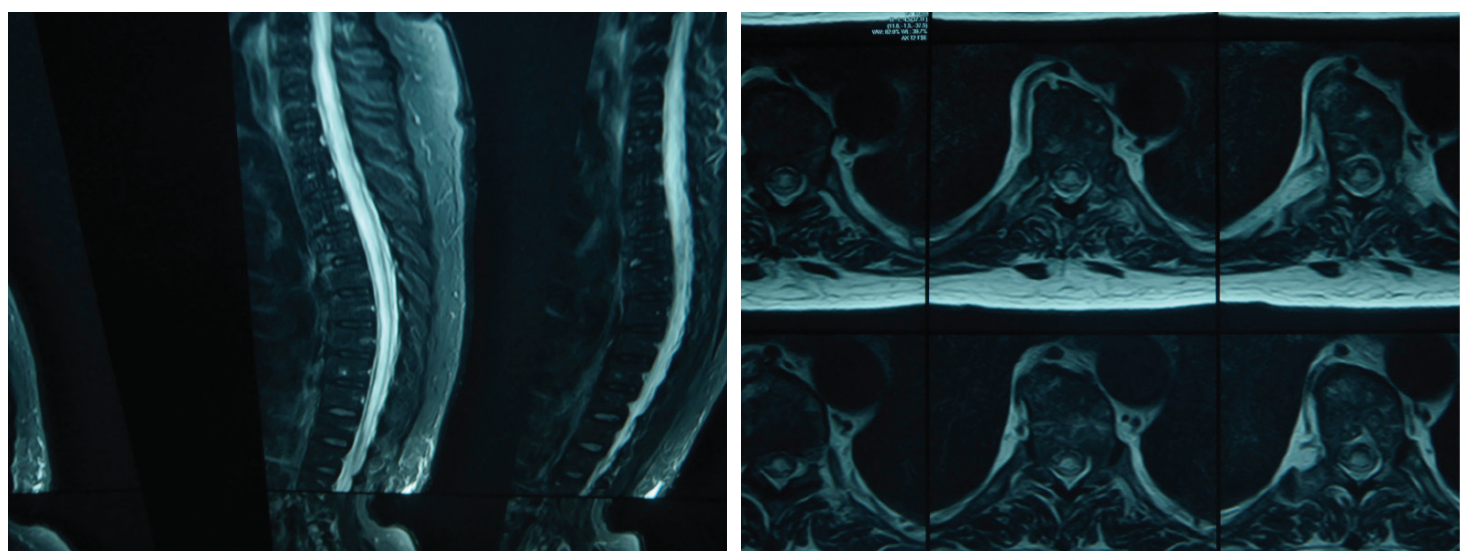

Figure. Extensive spinal cord lesion in a 75-years-old patient (sagittal and transversal images). 


\section{References}

1. Nandhagopal R, Al-Asmi A, Gujjar AR. Neuromyelitis optica: an overview. Postgrad Med J 2010;86:153-159.

2. Wingerchuk DM, Lennon VA, Pittock SJ, Lucchinetti CF, Weinshenker BG. Revised diagnostic criteria for neuromyelitis optica. Neurology 2006;66:1485-1489.

3. Papais-Alvarenga RM, Miranda-Santos CM, Puccioni-Sohler M, et al. Optic neuromyelitis syndrome in Brazilian patients. J Neurol Neurosurg Psychiatry 2002;73:429-435.

4. Bichuetti DB, Oliveira EM, Souza NA, Rivero RL, Gabbai AA. Neuromyelitis optica in Brazil: a study on clinical and prognostic factors. Mult Scler 2009;15:613-619.

5. Adoni T, Lino AM, da Gama PD, et al. Recurrent neuromyelitis optica in Brazilian patients: clinical, immunological, and neuroimaging characteristics. Mult Scler 2010;16:81-86.

6. Mandler RN, Davis LE, Jeffery DR, Kornfeld M. Devic's neuromyelitis optica: a clinicopathological study of 8 patients. Ann Neurol 1993;34:162-168.
7.

Staugaitis SM, Roberts JK, Sacco RL, Miller JR, Dwork AJ. Devic type multiple sclerosis in an 81 year old woman. J Neurol Neurosurg Psychiatry 1998;64:417-418.

8. Nakano Y, Miyamoto K, Inatsugi Y, Suzuki H, Kusunoki S. Senileonset recurrent myelitis with anti-aquaporin-4 antibody. Brain Nerve 2009;61:601-604

9. Satoh S, Hoshi K, Watanabe M, Hineno A, Oyanagi K, Yahikozawa H. An autopsied case of postinfectious neuromyelitis optica in an 84-yearold man. Rinsho Shinkeigaku 2011;51:538-539.

10. Lefaucheur R, Bourre B, Ahtoy P, et al. Neuromyelitis optica with very late onset. J Am Geriatr Soc 2011;59:1138-1140.

11. Sato D, Brazilian Committee for Treatment and Research in Multiple Sclerosis et al. Treatment of neuromyelitis optica: an evidence based review. Arq Neuropsiquiatr 2012;70:59-66. 